\title{
Insertional Mutagenesis and Cloning of the Gene Required for the Biosynthesis of the Non-Host-Specific Toxin in Cochliobolus lunatus that Causes Maize Leaf Spot
}

\author{
Jin-Xin Gao, Tong Liu, and Jie Chen
}

First, second, and third authors: School of Agriculture and Biology, Shanghai Jiaotong University, Key Laboratory of Urban Agriculture (South), Ministry of Agriculture, 800 Dongchuan Road, Shanghai 200240, P.R. China; and second author: School of Agriculture, Heilongjiang Bayi Agricultural University, Daqing 163319, Heilongjiang, P.R. China.

Accepted for publication 2 October 2013.

\begin{abstract}
Gao, J.-X., Liu, T., and Chen, J. 2014. Insertional mutagenesis and cloning of the gene required for the biosynthesis of the non-host-specific toxin in Cochliobolus lunatus that causes maize leaf spot. Phytopathology 104:332-339.

The maize pathotype Cochliobolus lunatus causes Curvularia leaf spot by producing a non-host-specific toxin known as methyl 5-(hydroxymethyl) furan-2-carboxylate (M5HF2C). However, related research that explores the genes that control the production of this toxin is rare. In the current work, Agrobacterium tumefaciens-mediated transformation (ATMT) was employed to tag the gene required for the biosynthesis of

grated plasmid was recovered from one of the mutants. A cosmid clone of the wild-type strain was isolated using the recovered DNA as a probe. The results of the structural and functional analyses of the region corresponding to the tagged site were then used as a basis to successfully clone one gene, called Clt-1. Bioinformatics analysis showed that the gene coded a BTB domain-containing protein that comprises 745 amino acids. Southern analysis revealed that the gene was localized in the genome as a single copy. The essential roles of $\mathrm{Clt}-\mathrm{I}$ in both toxin production and pathogenicity were confirmed by gene disruption experiments. In summary, the novel gene $C l t-1$ is closely associated with toxin production and pathogen virulence in leaves of susceptible varieties.
\end{abstract} the toxin. Of the 3,000 ATMT transformants recovered, 4 showed a significant decline in pathogenicity on maize leaves; 1 transformant, T806, produced no detectable M5HF2C. Genomic DNA that flanks the inte-
Additional keyword: melanin.
Curvularia leaf spot in maize caused by Cochliobolus lunatus R. R. Nelson \& F. A. Haasis is one of the most widely distributed maize foliar diseases in the world; it accounted for the reduced maize yield in northern China in the 1990s $(6,7,21)$. At present, this disease is widespread in the provinces of Henan, Anhui, and Liaoning. Despite the increased distribution of the pathogen in maize-growing areas in China, few studies have investigated the factors involved in the pathogenesis of $C$. lunatus. Consequently, effective measures to control fungal disease are difficult to establish.

Thus far, there is little reported research on pathogenicity mechanism of $C$. lunatus. Some reports revealed that $C$. lunatus can produce cell-wall-degrading enzymes and toxins but details pertaining to the interaction of the pathogenic factors during infection were not given. Over the last couple of years, the structure of the toxin has been elucidated (19), and several pathogenicity genes, including Brnl (20), Clkl (12), and Clml (29), have also been cloned and evaluated in terms of their function in virulence to maize. Although the chemical structure of the nonhost-specific toxin has been identified, knowledge of its biosynthesis is still limited. A conventional genetic analysis of $C$. lunatus cannot be carried out because the sexual cycle of this species in natural conditions is unknown. To understand the molecular

Corresponding author: J. Chen; E-mail address: jiechen59@ sjtu.edu.cn

*The $\boldsymbol{e}$-Xtra logo stands for "electronic extra" and indicates that Figures 1, 3, 6, and 8 appear in color online.

http://dx.doi.org/10.1094/PHYTO-07-13-0190-R

(c) 2014 The American Phytopathological Society basis of pathogenesis, the present study explores the cloning of the genes required in the biosynthesis of this non-host-specific toxin.

In the last three decades, methods such as restriction enzymemediated integration, polyethylene glycol-mediated transformation, and Agrobacterium tumefaciens-mediated transformation (ATMT) have been widely applied to transform a wide range of pathogenic fungi $(11,22,27)$ and to conduct large-scale genomewide mutagenesis (23). ATMT was developed for efficient transformation and tagging mutagenesis in fungi $(5,8,23)$. This technique was successfully used to tag and clone a type $2 \mathrm{~A}$ phosphoprotein phosphatase gene as well as an SPT3 transcription factor gene in Botrytis cinerea; the latter demonstrated a significant impact on virulence (13). Enhanced transformation efficiencies and mutagenesis in $C$. lunatus by ATMT have also been reported (18).

The goal of this study was to identify a gene associated with the production of the non-host-specific toxin. Random insertional mutants of $C$. lunatus were generated from a large population of mutants using ATMT. The insertional mutants were screened for deficiency in pathogenicity or toxin production. The flanking sequences surrounding the insertion sites were subsequently cloned to obtain the full length of the gene sequence. Finally, gene disruption experiments were carried out to perform functional analysis.

\section{MATERIALS AND METHODS}

Fungal strains, plant materials, and general growth conditions. Highly virulent strain CX-3 of $C$. lunatus was used as a recipient for fungal transformation. A Clt-1 gene-deletion strain, 
$\Delta$ Clt-1, was generated in the $\mathrm{CX}-3$ genomic background. $\Delta \mathrm{Clt}-1-\mathrm{C}$ is the $\Delta$ Clt-1 strain complemented with the wild-type (WT) Clt-1 gene. Unless mentioned otherwise, all strains were grown on potato dextrose agar (PDA) at $28^{\circ} \mathrm{C}$ in the dark. Zea mays 'Huangzao-4' was grown in a growth chamber under $14 \mathrm{~h}$ of light and $10 \mathrm{~h}$ of darkness at $25^{\circ} \mathrm{C}$, as previously described (20).

Nucleic acid analysis. To extract fungal DNA or RNA, the strains were grown in $100 \mathrm{ml}$ of PD medium in 250-ml Erlenmeyer flasks with continuous shaking at $160 \mathrm{rpm}$ for $72 \mathrm{~h}$ at $28^{\circ} \mathrm{C}$. The mycelia produced from these cultures were harvested by filtration using three layers of sterile cheese cloth, washed with sterilized double-distilled (dd) $\mathrm{H}_{2} \mathrm{O}$, and ground in liquid nitrogen. Fungal genomic DNA was extracted using a plant genomic DNA kit (Tiangen Biotech Company, China), whereas plasmid DNA was extracted using a plasmid DNA preparation kit (Tiangen Biotech Company). Total RNAs were extracted from the powdered mycelia by using Trizol Reagent (Invitrogen), following the manufacturer's instructions. The total RNAs were then treated with DNaseI (Takara, Japan) to remove genomic DNA. Firststrand cDNA was synthesized using the PrimeScript RT Reagent Kit (Takara). Southern analysis was performed with a commercial kit (GE Healthcare, Germany) using standard procedures.

ATMT of $C$. lunatus. The protocol for the A. tumefaciens transformation of $C$. lunatus was modified and adjusted as follows (18). The pBHt-1 vector was used for ATMT. This vector contains the hygromycin B resistance cassette composed of the Escherichia coli hygromycin phosphotransferase gene (hph) under control of the trpC promoter and terminator from Aspergillus nidulans.

A single colony of Agrobacterium tumefaciens containing the pBHt-1 vector was grown in Luria-Bertani medium containing kanamycin $(100 \mu \mathrm{g} / \mathrm{ml})$ at $28^{\circ} \mathrm{C}$ for $48 \mathrm{~h}$. The culture $(2 \mathrm{ml})$ was harvested by centrifugation ( $2 \mathrm{~min}$ at $10,000 \mathrm{rpm}$ ), and the ensuing pellet was washed with $1 \mathrm{ml}$ of induction medium (IM) (18). The cells were resuspended in $40 \mathrm{ml}$ of IM amended with $200 \mu \mathrm{M}$ acetosyringone and cultured for $6 \mathrm{~h}$ at $28^{\circ} \mathrm{C}(220 \mathrm{rpm})$ until an optical density $(600 \mathrm{~nm})$ of 0.6 was reached.

Bacterial cells and the conidial suspension of $C$. lunatus $(1 \times$ $10^{6}$ conidia/ml) were mixed (1:1). Afterward, $200 \mu$ lof the mixture was allowed to grow at $24^{\circ} \mathrm{C}$ for $48 \mathrm{~h}$ on each nitrocellulose filter placed on a co-cultivation medium. The filters were then transferred to a medium containing hygromycin $\mathrm{B}$ $(200 \mu \mathrm{g} / \mathrm{ml})$ as a selection agent for transformants of $C$. lunatus and cefotoxime $(300 \mu \mathrm{g} / \mathrm{ml})$ to eliminate A. tumefaciens cells. Typically, transformants of $C$. lunatus appeared after 6 to 7 days of incubation at $28^{\circ} \mathrm{C}$ in the dark. Resistant colonies were transferred to PDA medium with cefotoxime $(300 \mu \mathrm{g} / \mathrm{ml})$. After 7 days, the primary transformants were subjected to one round of single-spore isolation and subsequently transferred to plates containing hygromycin B to test the stability of the integrated T-DNA.

Cassette polymerase chain reaction. Modified cassette polymerase chain reaction (PCR) was used to rescue DNA sequences adjacent to the T-DNA integration site. A DNA sample $(2 \mu \mathrm{g})$ from T806 was digested with EcoRI, HindIII, PstI, SalI, and $\mathrm{XbaI}$ restriction enzymes $(5 \mathrm{U})$ overnight at $37^{\circ} \mathrm{C}$ in $50-\mu \mathrm{l}$ reactions. The digested DNA was purified via phenol-chloroform extraction and absolute ethanol precipitation. The DNA pellet was dissolved in $10 \mu \mathrm{l}$ of $\mathrm{ddH}_{2} \mathrm{O}$, and the digested DNA (100 ng) was ligated at $16^{\circ} \mathrm{C}$ for $5 \mathrm{~h}$ using T4 DNA ligase (Takara). The ligated DNA was also purified via phenol-chloroform extraction and absolute ethanol precipitation. The DNA pellet was then dissolved in $10 \mu \mathrm{l}$ of $\mathrm{ddH}_{2} \mathrm{O}$.

PCR amplification of the right border (RB) flanking sequence was performed with the ligation product as template using specific nested primers (Tn-1 and Tn-2) and cassette primers ( $\mathrm{C} 1$ and C2). Meanwhile, the left border (LB) flanking sequence was amplified using specific nested primers (Tn-3 and $\mathrm{Tn}-4)$ and cassette primers ( $\mathrm{C} 1$ and $\mathrm{C} 2$ ). The specific fragments were gel purified and ligated into the pMD18-T vector (Takara) prior to sequencing.

The resulting assembled sequence was used to search for similarities in the National Center for Biotechnology Information websites (http://www.ncbi.nlm.nih.gov) via the Blastx and Blastn algorithms (1). Additional open reading frame (ORF) prediction was carried out with ORF Finder (http://www.ncbi.nlm.nih. gov/gorf).

Cloning of full-length $\boldsymbol{C l t}$ - $\mathbf{I}$ gene and sequence analysis. A pair of primers A and B (Table 1) was designed based on the

TABLE 1. Primers used for this study

\begin{tabular}{|c|c|c|c|c|}
\hline Primers & Sequence $5^{\prime}$ to $3^{\prime w}$ & Description $^{\mathrm{x}}$ & PCR $(\mathrm{kb})^{\mathrm{y}}$ & Purpose $^{\mathrm{z}}$ \\
\hline hyg-F & CGACAGCGTCTCCGACCTGA & $h p h$ coding region, $\mathrm{FP}$ & 0.811 & $\begin{array}{l}\text { cDNA clone, insertion mutation, } \\
\text { and } \Delta \text { Clt- } 1 \text { confirmation }\end{array}$ \\
\hline hyg-R & CGCCCAAGCTGCATCATCGAA & $h p h$ coding region, $\mathrm{RP}$ & . & $\ldots$ \\
\hline Primer A & CCTCGACCTTTGCTGAGTAT & Clt -1 coding region, $\mathrm{FP}$ & 0.767 & $\Delta$ Clt- 1 and $\Delta$ Clt- $1-\mathrm{C}$ confirmation \\
\hline Primer B & TGTGAAGCACCCGCGATACG & Clt -1 coding region, $\mathrm{RP}$ & $\ldots$ & $\ldots$ \\
\hline $\operatorname{Tn}-1$ & GGATAGCAGCACGCAATTCCATTGTG & Specific nested primer, RB_FP1 & $\ldots$ & RB flanking sequence \\
\hline Tn-2 & AACAGATGTGCGTGATCTTCTGCCTC & Specific nested primer, RB_FP2 & $\ldots$ & $\ldots$ \\
\hline Tn-3 & CAGGCATTCTTCACCCCGTCTGAGA & Specific nested primer, LB_RP1 & $\ldots$ & LB flanking sequence \\
\hline $\operatorname{Tn}-4$ & TGTTCACTCACGGTTCGCTCATTGG & Specific nested primer, LB_RP2 & $\ldots$ & $\ldots$ \\
\hline $5^{\prime}$-race & GGTGTTCTCGTCTTGGGT & $5^{\prime}$-race-specific primer & $\ldots$ & $5^{\prime}$ end of cDNA sequence \\
\hline $3^{\prime}$-race & GACGCCGAAGAGATTGACGAC & $3^{\prime}$-race-specific primer & $\ldots$ & $3^{\prime}$ end of cDNA sequence \\
\hline 1 & GTTGAGGGCATTTCTTGTTT & Flanking region upstream of $C l t-1 \mathrm{FP}$ & 1.538 & $\Delta$ Clt-1 \\
\hline \multirow[t]{2}{*}{$2+\mathrm{C} 3$} & CATTGATGTGTTGACCTCC AGGTGTTCTC & & & \\
\hline & GTCTTGGGT & Flanking region upstream of $C l t-1 \mathrm{RP}$ & $\cdot$ & $\ldots$ \\
\hline 3 & GGAGGTCAACACATCAATG & FP to amplify $H y g B$ & 1.004 & $\ldots$ \\
\hline 4 & TTGGCGACCTCGTATTGG & $H y g B$ split marker RP & $\ldots$ & $\ldots$ \\
\hline 5 & TGTCCTGCGGGTAAATAGC & $H y g B$ split marker FP & 0.891 & $\ldots$ \\
\hline 6 & СТАСТСТАТТССТTTGCССТCG & RP to amplify $H y g B$ & $\ldots$ & $\ldots$ \\
\hline \multirow[t]{2}{*}{$\mathrm{C} 6+7$} & CGAGGGCAAAGGAATAGAGTAGACGAGC & & & \\
\hline & ACCACCGAAACT & Flanking region downstream of $C l t-1 \mathrm{FP}$ & 1.389 & $\ldots$ \\
\hline 8 & GCTGGAATCCCATTACCTAT & Flanking region downstream of $C l t-1 \mathrm{RP}$ & $\ldots$ & $\ldots$ \\
\hline Fn1 & CCGCTCGAGCTGACTGATGTTACGGACTC & FP upstream of $C l t-1$ promoter primer & 3.591 & $\Delta$ Clt-1-C \\
\hline Fn2 & CCGGAATTTCATTTCGCTACGCTAGGGC & Clt -1 coding region, $\mathrm{RP}$ & $\ldots$ & $\ldots$ \\
\hline
\end{tabular}

${ }^{\mathrm{w}}$ Underlined regions identify added restriction sites.

${ }^{x} \mathrm{FP}=$ forward primer and $\mathrm{RP}=$ reverse primer.

y Polymerase chain reaction (PCR) product length.

z Symbol: $\Delta=$ gene deletion. 
predicted conserved sequence of the Clt-1 gene. The $5^{\prime}$ - or $3^{\prime}$ flanking sequence was obtained using a SMART RACE cDNA Amplification Kit (Clontech, CA). The reaction solution consisted of $5 \mu$ l of template $\left(5^{\prime}\right.$ or $3^{\prime}$ rapid amplification of cDNA ends [RACE] cDNA), $2 \mu \mathrm{l}$ of specific primer (5'-race or $3^{\prime}$-race; $\left.10 \mu \mathrm{M}\right)$, $5 \mu \mathrm{l}$ of UPM, $1 \mu \mathrm{l}$ of dNTP Mix $(10 \mathrm{mM}), 5 \mu \mathrm{l}$ of $10 \times$ Extensor Buffer 1 or $2(22.5 \mathrm{mM} \mathrm{MgCl} 2), 0.5 \mu \mathrm{l}$ of Extensor Hi-Fidelity PCR Enzyme Mix (5 U/ $\mu \mathrm{l})$, and $31.5 \mu \mathrm{l}$ of $\mathrm{ddH}_{2} \mathrm{O}$. The amplification protocol was one cycle at $94^{\circ} \mathrm{C}$ for $1 \mathrm{~min}$; followed by 30 cycles at $94^{\circ} \mathrm{C}$ for $30 \mathrm{~s}, 60^{\circ} \mathrm{C}$ for $30 \mathrm{~s}$, and $72^{\circ} \mathrm{C}$ for $3 \mathrm{~min}$; a final 10 -min extension was conducted at $72^{\circ} \mathrm{C}$. The amplification products of $5^{\prime}$ and $3^{\prime}$ RACE PCR were gel purified, ligated into the pMD18-T vector (Takara), and sequenced. The full-length cDNA of Clt-1 was obtained through sequence assembly by searching for regions with overlapping sequences.

Gene deletion, PCR confirmation, and complementation. Clt- 1 was deleted using the split marker method $(10,34)$ and the transformation protocol described previously (18). Confirmation of the integration at the target sites and the complementation of the Clt-1 mutant through the Southern analysis were performed following the protocol of Liu et al. (18). Fn1 and Fn2 primers were used to amplify the promoter and the full-length sequence of Clt-1. The plasmid pBHt-Clt- 1 was constructed by replacing the PtrpC and $h p h$ fragment with the amplified sequence. In addition, plasmid pBHt-Cltl-ble was generated by inserting a $4.5-\mathrm{kb}$ fragment containing the complete ble gene from pME2891 into pBHt-Clt-1. The final construct carrying both the WT Clt-1 and the ble selectable marker was used to transform $\Delta$ Clt- 1 and subsequently create a Clt-1-restoring strain. The sequences of primers used for gene deletion, PCR confirmation, and complementation are listed in Table 1.

Analysis of vegetative growth, conidiation, and penetration. A $0.5-\mathrm{cm}^{2}$ agar block of $C$. lunatus strains was transferred onto a PDA medium at $28^{\circ} \mathrm{C}$ in the dark. The diameters of the colonies were measured in millimeters once a day over a 5-day period. Conidia formed on PDA were harvested from 12-day-old mycelia cultures of each strain with $5 \mathrm{ml}$ of sterile $\mathrm{ddH}_{2} \mathrm{O}$ and were immediately counted with a hemocytometer. Then, 20- $\mu$ d droplets of conidial suspension $\left(1 \times 10^{4}\right.$ conidia/ml $)$ from 6- to 8-day-old cultures were placed on each piece of prewashed GelBond. Onion epidermises with $10 \mu \mathrm{l}$ of conidial suspension $\left(1 \times 10^{4}\right.$ conidia $\left./ \mathrm{ml}\right)$ were cultured at $25^{\circ} \mathrm{C}$ for $24 \mathrm{~h}$. The appressorium formation rates of $C$. lunatus strains on onion epidermal cells were scored with a light compound microscope (17,30). All treatments were performed in quadruplicate, and the assays were conducted at least thrice.

Virulence and toxin assay. Virulence of C. lunatus was evaluated as previously described (20). The fourth leaves of the susceptible maize seedlings at the seven-leaf stage were inoculated with
$10 \mu \mathrm{l}$ of conidial suspension $\left(1.0 \times 10^{6}\right.$ conidia $\left./ \mathrm{ml}\right)$ per leaf. Transformants that demonstrated unstable virulence in duplicate assays were excluded. Photographed leaves were imaged in Photoshop CS5, and lesion length was measured with a ruler. The disease severity was assessed between treatments according to the foliar disease rank standard $(12,20)$. All treatments were performed in quadruplicate, and the assays were conducted at least thrice. Statistical analysis was accomplished by $t$ test.

To determine whether the mutants retained the ability to produce the virulence-related toxin methyl 5-(hydroxymethyl) furan2-carboxylate (M5HF2C), they were cultured in Fries medium (number 3) (19). The crude extract was dissolved in ethanol and subjected to separation through thin-layer chromatography (TLC) (Silica gel 60 F254, $0.5 \mathrm{~mm}$; Merck, Germany) with a butanol/ acetone/water solvent system of 4:5:1 (by volume). These experiments were conducted in triplicate.

\section{RESULTS}

Construction of virulence mutant library and screening. A collection of 3,000 hygromycin-resistant transformants was generated using an optimized ATMT protocol (18). The transformants were genetically purified via one round of single-spore isolation and routinely checked by PCR to confirm the integration of the hygromycin resistance cassette conveyed by the pBHt-1 vector. Southern analysis of the randomly chosen transformants indicated that most of the mutants contained single integrations of the T-DNA. In addition, the different sizes of the T-DNA-containing fragments indicated random integration (data not shown).

All the transformants with a single insert of T-DNA were prescreened in a detached maize leaf to evaluate changes in their virulence. The comparison between the disease symptoms caused by mutants and the WT strain relative to control is shown in Figure 1A. Most mutants exhibited WT-like infection patterns (e.g., T801, T1648, and T2001). However, lesion sizes on susceptible corn leaves inoculated with T2, T806, T899, or T950 were significantly reduced compared with WT (Fig. 1B). Further screening showed that T806 was the only mutant that had nondetectable levels of M5HF2C (Fig. 2).

Rescue of T-DNA flanking regions and analysis of T-DNA integration site. The virulence-attenuated mutant T806, which clearly showed a single integration event, was subjected to a detailed molecular study. To isolate the genomic regions adjacent to the left and right borders of the T-DNA integration event, cassette PCR was performed on this transformant.

The T806 border sequences (LB and RB) were successfully rescued and further analyzed to determine any overlapping with the pBHt-1 vector used for the Agrobacterium transformation. Sequences of implicated cassette PCR products were assembled
$\mathbf{A}$

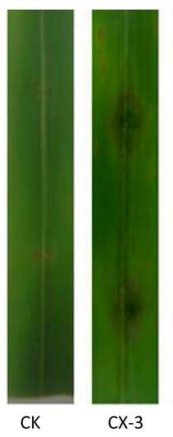

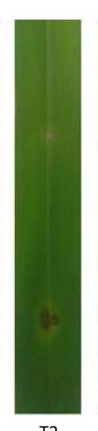

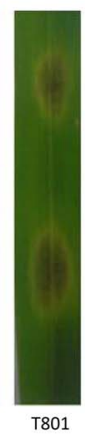

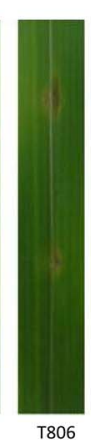
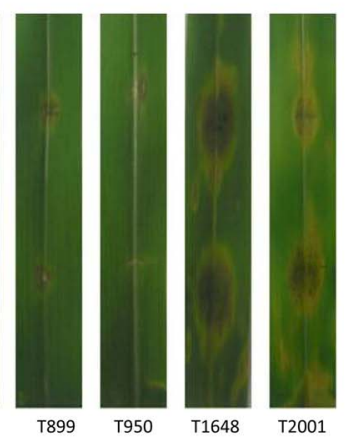

B

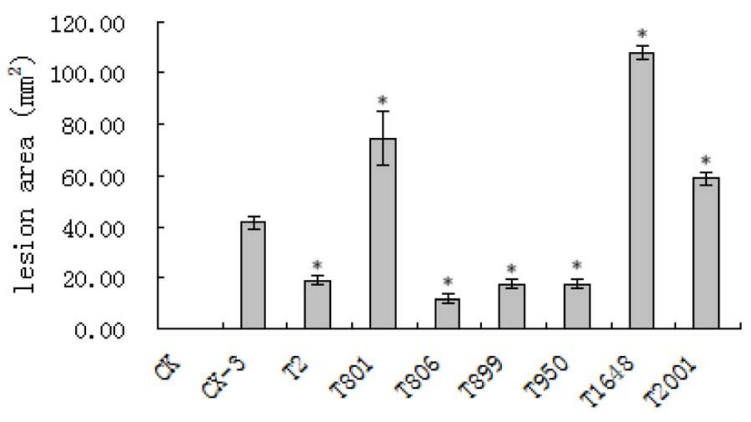

Fig. 1. Infection assays using the early maize 'Huangzao-4' to assess the virulence of strains of Cochliobolus lunatus transformed by random insertional mutagenesis. A, Inoculated leaves showing symptoms of Curvularia leaf spot $72 \mathrm{~h}$ after inoculation. B, Quantification of disease on susceptible corn leaves shown in A. Error bars represent standard deviation. Asterisks indicate $P$ value $<0.05$ in $t$ test analysis, in which all mutants were compared with wild-type (CX-3) grown in the same condition. CK: double distilled water. 
to identify T-DNA insertion sites. Analysis of the T806 mutant via cassette PCR sequence revealed that the assembled sequence contains three structural genes, and that the T-DNA was inserted in the promoter region of the second structural gene, named Clt-1 (Fig. 3A). This Clt-1 protein has $63 \%$ identity with a hypothetical protein of Phaeosphaeria nodorum SN15 (SNOG 13355), which contains a highly conserved Drosophila transcription factors Brica-brac, Tramtrack, and Broad Complex (BTB) superfamily domain (35) in its $\mathrm{N}$ terminus and an unknown sequence in its $\mathrm{C}$ terminus (Fig. 3B). Overall, the gene has low similarity with those found in other fungal species.

Full-length Clt-1 cDNA cloning and sequence analysis. Fragments measuring 2,384 and 2,238 bp were obtained from the genomic DNA of $C$. lunatus and from first-strand cDNA, respectively, by PCR amplification. Two introns (146 bp: Clt-1 197 to 251 and 1,209 to $1,299 \mathrm{bp}$ ) were determined by aligning the genomic DNA and cDNA sequences of Clt-1 using DNA-MAN 6.0 software. The ORF of $C l t-1$ encoding a 745 -amino-acid protein was verified to have a BTB domain-containing protein (Fig. 3). The sequence of the Clt-1 gene has been deposited in GenBank (accession number GQ292557).

The copy number of Clt-1 in the $C$. lunatus genome was determined by Southern analysis prior to the functional studies. No restriction sites for the enzymes SalI, EcoRI, and HindIII were present and only one site for PstI was observed in the sequence of the $C l t-1$ gene. One band of SalI, EcoRI, and HindIII as well as two bands of PstI hybridized to the Clt- 1 probe (Fig. 4), indicating that the gene may be present as a single copy in the $C$. lunatus genome.

Effect of deletion of Clt-1 on the ability to infect and colonize maize leaf. To verify whether the Clt-1 gene is indeed responsible for the observed phenotype of the T806 mutant, disruption of the tagged gene in the WT strain was performed as previously described; the approach was also employed to confirm the link between the phenotype of T806 and T-DNA integration (24).

A fragment containing the hygromycin B resistance cassette, as well as the borders flanking the $5^{\prime}$ - and $3^{\prime}$-primed end genes, was excised from the deletion vector pBHt-1 (Fig. 3A) and used to transform protoplasts of the WT strain CX-3. A 1,669-bp fragment from $C l t-1$ ( 1 to $1,669 \mathrm{bp}$ ), including the BTB domain-containing protein, was expected to be replaced. Diagnostic PCR and

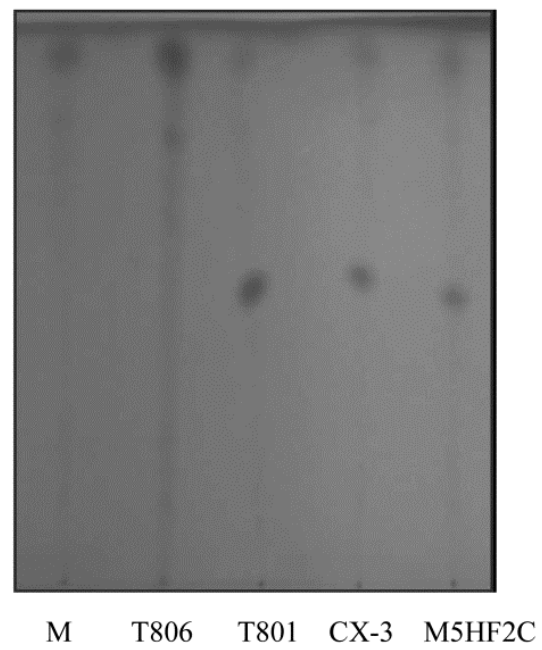

Fig. 2. Thin-layer chromatography (TLC) analysis of methyl 5-(hydroxymethyl) furan-2-carboxylate (M5HF2C) toxin in Agrobacterium tumefaciensmediated transformation transformants. Mutant T801 produced M5HF2C like the wild-type (CX-3), whereas T806 lost the capacity to produce M5HF2C. M: Modified Fries medium (number 3). M5HF2C standard is shown on the right side of the TLC plate.
Southern analysis confirmed there were six transformants with homologous integration events (Fig. 5).

Preliminary characterization of the obtained mutant revealed that $\Delta$ Clt-1 had a phenotype similar to that of the original insertion mutant T806 in both axenic culture and in planta; the similarity could specifically be observed on their morphologies and growth of mutant colonies. Both $\Delta$ Clt- 1 and T806 reduced conidia formation over an order of magnitude and had a slightly decreased infectivity on the onion epidermises compared with the WT strain CX-3. The two strains were lighter in color relative

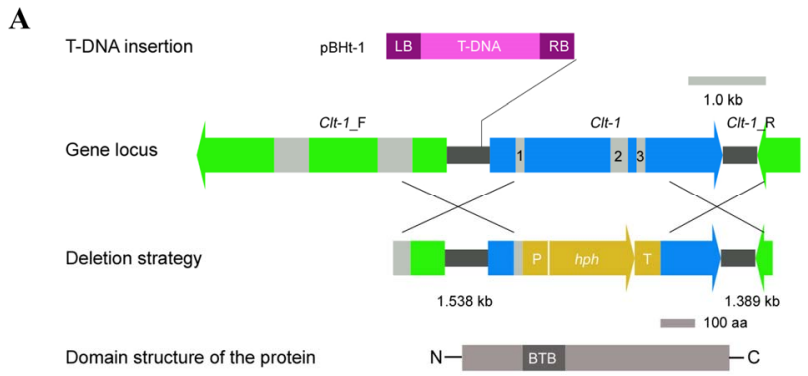

B

SNOG1335

MPLVALRHDTRRGRASPSHLHSARRQHGDDIIKTTHCLHPNVLTALLTRAIRLAFMSAPI (1)

$\mathrm{Clt}-1$

SNOG13355

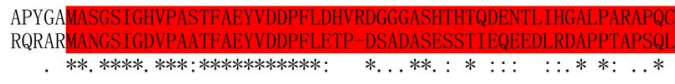

Clt-1

SNOG13355

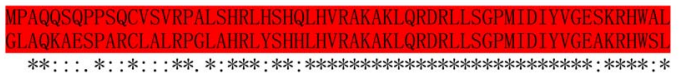

Clt-1

SNOG13355

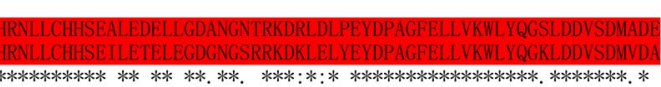

Clt-1
SNOG13355

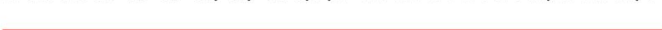

SNOG1335

NQKYEYAVSCHKLYLLCDRLDMPQLKNVAMIQYRKGLNQAELVPDDADEIDEIYRKSPVGS

Clt -1

SNOG13355

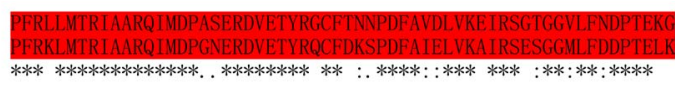

C1t-1

SNOG13355

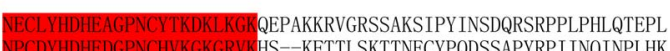

Clt -1

SNOG13355

PAPPLPTRPRERNPLRRCLTSPVSSTVGTSKEMAVATQPFKEALRDREKDIERLRKVSPP LRPASPPSPPASKNASPASSSPSSPSRPGRGSAAPSPDQSGDLNSWYFTGNGDGKSAAQ

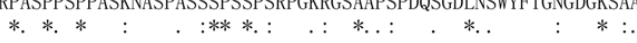

Clt -1

SNOG13355

ERKRLGPTQINGTKTHESHPALDEHHRNSEDTYRPAKDSQAASGSDGEGEGGPVQPLQTS

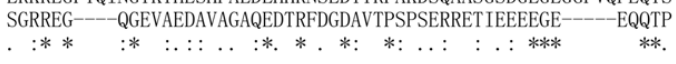

Clt -1 SRRGIWEWAKAGTGRLGMIGSIPEAQEDGFDISTAITSEKNDLQPDEQTPPSKVTVFGLS SNOG13355 SRRGLWEWARNGSARLDLIGRIPRPEWRGPVFIRNRD-----TVETQDDFSVPSSTAT $* * * * * * * *: * . . * * .: * * * * . .: *$ : $\quad * \quad$. *.

Clt-1 HSNIAPSPSFSQTKRSSDELVAASSTTTTPATLNRPTQSWTNGKQITPMPISEHSPPLTP $\begin{array}{ll}\text { Clt }-1 & \text { HSNIAPSPSFSQTKRSSDELVASSTTTTPATLNRPTQSWTNGKQITPMPISEHSPPLTP } \\ \text { SNOG13355 } & \text { EPDNVTSPSFAQTKQSSDDLIATASSTGSPAWQQNVDGAG------EACTPSKDSAISTP }\end{array}$

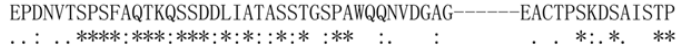

$\mathrm{Cl} \mathrm{t}-1$ DTPTPPQRRRTPVDTNGSTTPPKDAPAVESTPAAKPRSNGTSPAATSPATQTASDSTTT

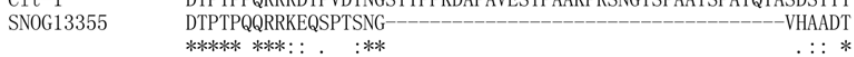

$\mathrm{Cl}-1$ PVRRYKIVLNPNMISPGRSSPSVAK

SNOG13355 PTKTPASALDPDVQNRTRAESSFVG

Fig. 3. Detailed analysis of the candidate gene identified by the Agrobacterium tumefaciens-mediated transformation approach. A, T-DNA insertion site, the open reading frame, and the pursued deletion strategy. Conserved domain in the predicted protein was identified by using the online software InterProScan. B, Clt-1/SNOG13355 amino acid alignments. Cochliobolus lunatus (GQ292557, Clt-1 745 amino acids), and Phaeosphaeria nodorum (SNOG13355, 639 amino acids) were aligned using ClustalW. Conserved BTB domain is marked in red highlights, asterisks indicate identical residues, colons indicate conserved residues, and periods mark semi-conserved residues. 
to $\mathrm{CX}-3$ but vegetative growth rate was not affected (Fig. 6; Table 2).

Recovery of the WT phenotype by transforming Clt-1 to a gene-disrupted transformant. The $\Delta$ Clt- 1 mutant was transformed with a plasmid containing the Clt-1 gene; the ble gene served as a selective marker. Southern analysis confirmed the introduction of the Clt-1 gene (Fig. 5). Resulting transformants exhibited typical WT characteristics, including pathogenicity, normal vegetative growth, and normal appressorium formation on the hydrophobic surface of GelBond. However, the capabilities of sporulation were just partially restored in $\Delta$ Clt-1-C (Table 2).

Role of Clt-1 in the production of M5HF2C toxin. The M5HF2C toxin can induce symptoms of infection on maize plants. To further understand the relevance of $\mathrm{Clt}-1$ to toxin production, $\Delta$ Clt- 1 and $\Delta$ Clt-1-C were grown in Modified Fries media (number 3 ) at $28^{\circ} \mathrm{C}$ for 15 days; the presence of the toxin in culture was detected by TLC. $\Delta$ Clt- 1 and T806 both lost the capacity to produce the M5HF2C toxin, whereas $\Delta \mathrm{Clt}-1-\mathrm{C}$ regained the ability to produce the toxin (Fig. 7). Thus, Clt-1 is closely involved in the biosynthesis of M5HF2C.

Clt-1 involved in pathogenicity. To confirm whether the Clt-1 gene is associated with pathogenicity in maize, the conidial suspensions of CX-3, T806, $\Delta \mathrm{Clt}-1$, and $\Delta \mathrm{Clt}-1-\mathrm{C}$ were inoculated on seedling maize leaves. $\Delta$ Clt- 1 and T806 showed decreased pathogenicity in maize leaf, and their lesion areas were also distinctly smaller than those of the WT (Fig. 8; Table 2). In contrast, Clt-1-complementary transformants demonstrated infectivity similar to that of WT strains on detached maize leaves. Meanwhile, compared with controls, appressorium formation of $\Delta$ Clt- 1 decreased nearly $25 \%$ on the onion epidermal cells, which also demonstrated that $C l t-1$ is closely involved in pathogenicity (Table 2).

\section{DISCUSSION}

Clt-1 gene may play the role of a regulator of related transcription factors in M5HF2C toxin production. In our previous study, we successfully identified M5HF2C as a nonhost-specific toxin produced from $C$. lunatus, a typical organism that causes maize leaf spot. The supervirulence capability of the toxin was also observed on numerous plant species, including $Z$. mays, Oryzae sativa, Sorghum bicolor, Lycopersicum esculentum, Capsicum annuum, and Nicotiana tabacum (19). The toxin is similar in structure to the toxin 5-hydroxymethy-furan-2carboxaldehyde produced from Setosphaeria turcica, a pathogen causing northern leaf blight of maize (9). Both toxins are 5-hydroxymethyl-furan compounds. Enzymes involved in the

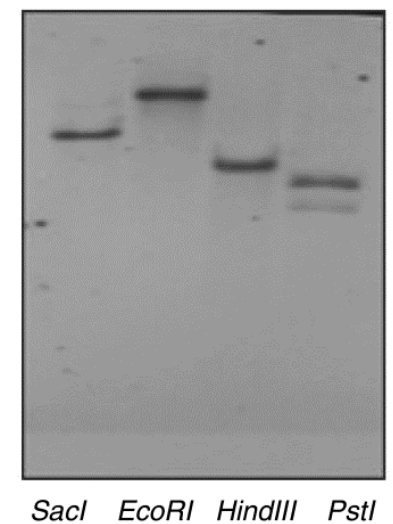

Fig. 4. Determination of Clt-1 copy number in genome of Cochliobolus lunatus isolate wild-type (CX-3) by Southern analysis. The genome DNA of C. lunatus isolate CX-3, digested with four different restriction enzymes (SalI, EcoRI, HindIII, and PstI) was hybridized with a Clt-1 probe; the 767-bp fragments of $C l t-1$ gene labeled with digoxigenin served as probe. biosynthetic pathway for 5-hydroxymethyl-furan toxins may be able to aminate, methylate, hydroxylate, and esterify stearic acid. However, the proteins directly responsible for the de novo biosynthesis of these toxins remain unknown. In addition, no study has reported about the genes responsible for this type of toxin production in vitro or in vivo. In the present work, the gene (Clt-1) from the pathogen closely associated with M5HF2C production was successfully cloned. However, the steps by which the gene regulates the production of the toxin have yet to be determined.

Clt-1 has a highly conserved BTB superfamily domain in its $\mathrm{N}$ terminus and an unknown sequence in its $C$ terminus (Fig. 3B). This characteristic is consistent with that of BTB-containing proteins: the charged groove that is conserved in the $\mathrm{N}$ terminus of the BTB transcription factor is a strong candidate as a docking site for peptides or other types of ligands; the differences in the Cterminus sequence determine whether the BTB domain drives the homo-, hetero-, or oligomerization of a given transcription factor, the function of which will be significantly affected. The BTB domain is an evolutionarily conserved protein-protein interaction motif that is found throughout eukaryotes. It can be combined with other domains to carry out multiple functions (28), such as gene transcriptional regulation pathway, ion channel gating, and protein degradation in various organisms $(2,15,25,26,35)$. The BTB-containing proteins in transcriptional regulation are widely reported in animals. Zollman et al. (35) isolated six additional Drosophila genes that encode a BTB domain; five of these genes were developmentally regulated and one was required for pattern formation along the proximal-distal axis of the leg and antenna.

\section{$\Delta$ Clt-1-C T806 T806 $\Delta$ Clt-1 CX-3}

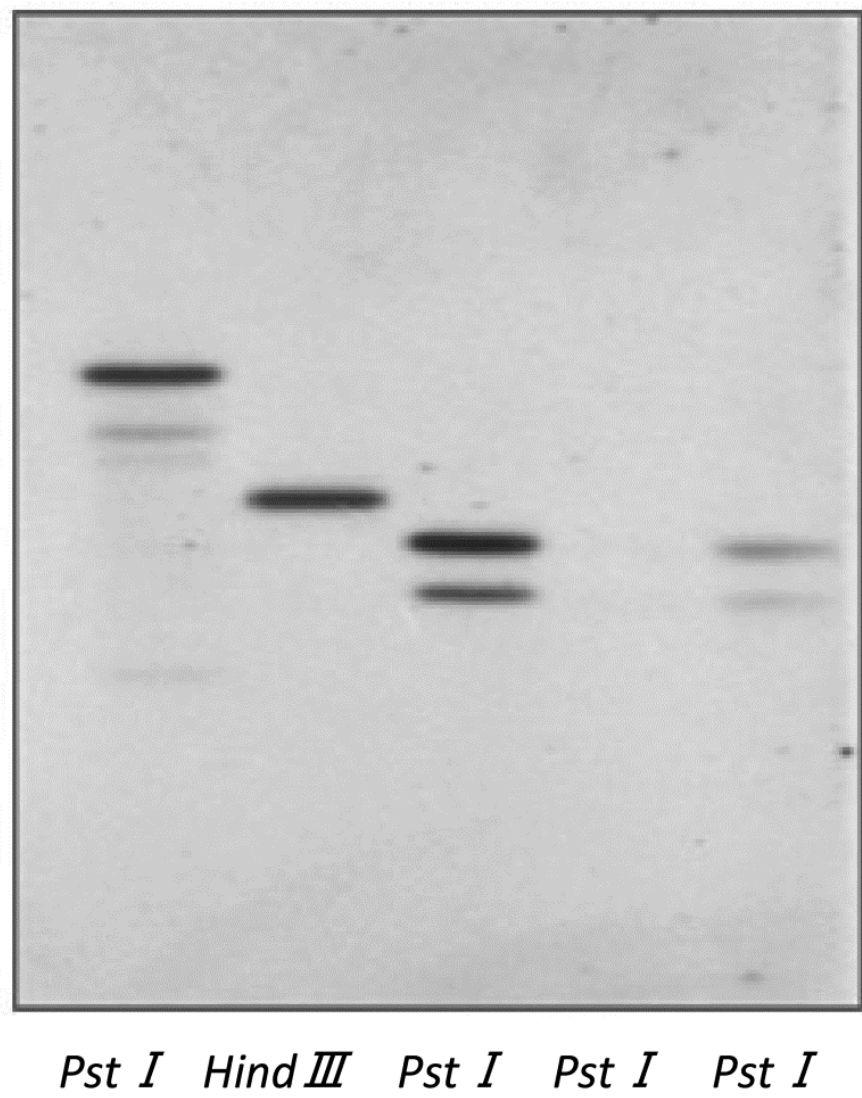

Fig. 5. Southern analysis of Clt-1 disruption and complementation. The genomic DNAs of wild-type (CX-3), Clt-1 deletion mutant ( $\Delta$ Clt-1), and $\Delta$ Clt- 1 mutant complemented ( $\Delta \mathrm{Clt}-1-\mathrm{C})$ strains were digested with PstI, whereas the transformant (T806) was digested with PstI and HindIII. The 767-bp fragment of the Clt-1 gene labeled with digoxigenin served as probe. 
Meanwhile, reports on the presence of this domain in fungal proteins are few. The present work may be the first report of a BTB-containing protein in a fungus known to be involved in toxin synthesis.

The Clt-1 protein is very likely to play the role of a regulator of related transcription factors rather than functioning as an enzyme responsible for toxin synthesis. In other words, the gene may regulate the expression of some crucial genes in the gene network closely related to M5HF2C biosynthesis. This assumption can only be confirmed through the identification of other toxin production-related proteins to which the Clt-1 interacts. A similar phenomenon was found in Aspergillus flavus: as a regulator gene, alfR can regulate the expression of structure genes norl, verl, omtA, ord1, ord2, pksA, uvm8, and aad, all of which are involved in aflatoxin production. These genes can be repressed in an alfR deletion strain and demonstrate a high expression level in alfR over-expression strain $(3,31)$. The TLC analysis combined with the gene-targeted disruption (only the BTB sequence is replaced with the $h p h$ gene) strains confirmed that the regulation mechanism of Clt-1 in the production of M5HF2C depends on its BTB domain. However, how Clt-1 regulates toxin production is yet to be determined.

Clt-1 may be associated with melanin production involved in pathogen virulence. Although the virulence of a Cochliobolus lunatus albino strain is indistinguishable from that of a pigmented strain under laboratory conditions, the lack of pigment compromises the fitness of the fungus under natural conditions (32). Melanin is known to consolidate the mechanical penetration structures of phytopathogens such as appressoria and infection pegs that are required in effective penetration. Melanin has also been confirmed to belong to virulence factors that can enforce the mechanical strength of infection into host plant epidermis in many plant diseases $(14,16,20)$.

In the present study, we found that the deletion of Clt- 1 leads to the loss of the dark color in C. lunatus (Fig. 6). The Brnl gene (GenBank accession number DQ358052) was functionally characterized as a gene that encodes a 1,3,8-trihydroxynaphthalene (THN) reductase, which converts 1,3,8-THN to vermelone or 1,8-dihydroxynaphthalene (DHN) in the DHN melanin synthesis pathway (20). This observation is in line with the result of the reverse-transcription PCR analysis to evaluate Brnl expression in $\Delta$ Clt-1 and T806, in which a significant downregulation can be observed (Fig. 9). Together, these observations demonstrate that $C l t-1$ positively regulates melanin production through the transcriptional control of the Brnl gene. In addition, Clt-1 and Brnl may have some connection or coordinated mediation mechanism in secondary metabolism. MgRac1 physically interacts with Chm1 and Nox via its p21-Rho-binding domain, which is also a protein-protein interaction motif in Magnaporthe terrestris. With the aid of MgRac-1, the Chm1 and Nox proteins are responsible for conidiogenesis and pathogenicity, respectively $(4,33)$. The BTB protein-interaction domain is important in the regulation of functional proteins. We speculate that Clt-1 may be

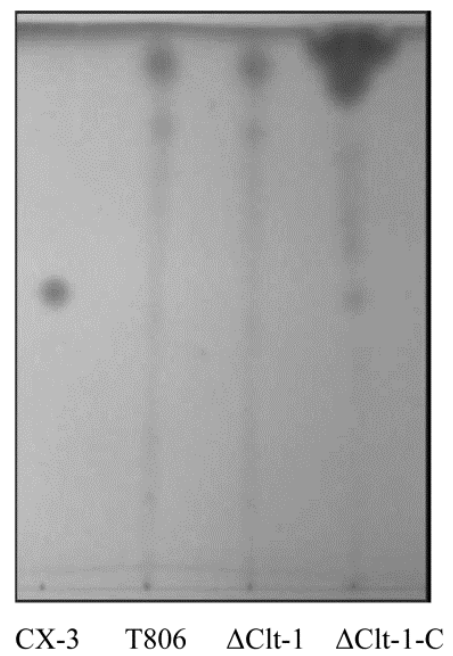

Fig. 7. Assay of the toxin produced from wild-type (CX-3), transformant (T806), Clt-1 deletion mutant $(\Delta \mathrm{Clt}-1)$, and $\Delta$ Clt-1 mutant complemented $(\Delta$ Clt-1-C) strains on thin-layer chromatography. $\Delta$ Clt-1 and mutant T806 lost the capacity to produce methyl 5-(hydroxymethyl) furan-2-carboxylate (M5HF2C) but $\triangle \mathrm{Clt}-1-\mathrm{C}$ regained the production of M5HF2C.

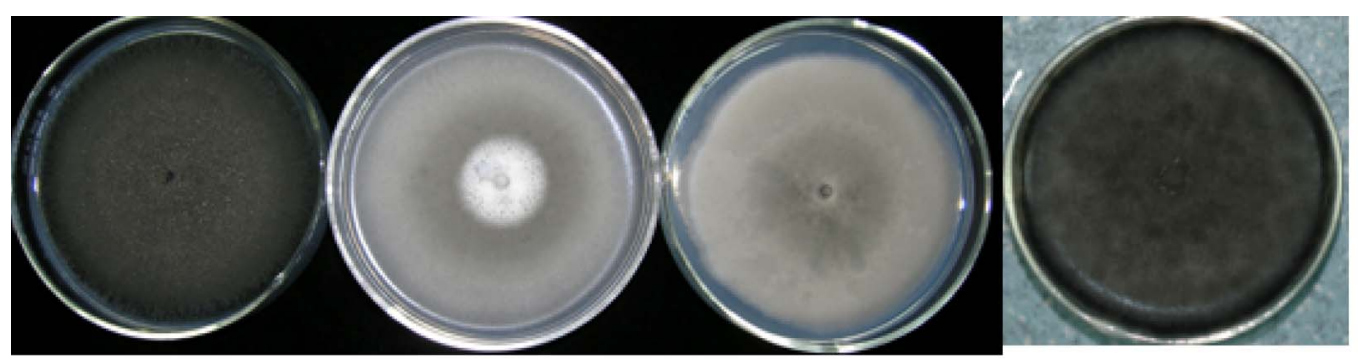

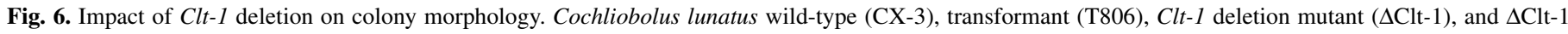

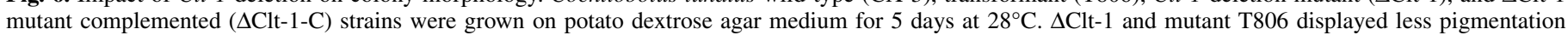
than $\mathrm{CX}-3$ but $\Delta \mathrm{Clt}-1-\mathrm{C}$ returned to normal production of melanin.

TABLE 2. Phenotypic analysis of Cochliobolus lunatus mutants compared with wild-type isolate CX-3

\begin{tabular}{|c|c|c|c|c|}
\hline Strain & Growth rate $(\mathrm{mm} / 24 \mathrm{~h})^{\mathrm{w}}$ & Conidiation $\left(\log _{10} \mathrm{CFU} / \mathrm{ml}\right)^{\mathrm{x}}$ & Necrosis area $\left(\mathrm{mm}^{2}\right)^{\mathrm{y}}$ & Penetration $(\%)^{\mathrm{z}}$ \\
\hline $\mathrm{CX}-3$ & $7.56 \pm 0.32$ & $6.54 \pm 0.01 \mathrm{a}$ & $40.17 \pm 8.46 \mathrm{a}$ & $77.77 \pm 3.85 \mathrm{a}$ \\
\hline T806 & $7.08 \pm 0.44$ & $5.03 \pm 0.15 \mathrm{c}$ & $2.12 \pm 1.91 \mathrm{c}$ & $58.00 \pm 7.08 \mathrm{bc}$ \\
\hline$\Delta$ Clt-1 & $7.07 \pm 0.51$ & $4.90 \pm 0.22 \mathrm{~d}$ & $5.11 \pm 4.11 \mathrm{c}$ & $51.00 \pm 11.09 \mathrm{c}$ \\
\hline$\Delta$ Clt-1-C & $6.89 \pm 0.23$ & $5.74 \pm 0.03 b$ & $32.11 \pm 1.31 \mathrm{~b}$ & $65 \pm 4.71 b$ \\
\hline
\end{tabular}

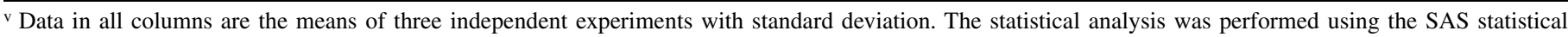
package. Statistically significant analysis of variance was further analyzed using least significant difference tests. Different letters in each data column indicate significant differences at $P=0.05$.

${ }^{w}$ Diameter of hyphal radii at day 5 after incubation on potato dextrose agar (PDA) plates at $28^{\circ} \mathrm{C}$.

${ }^{x}$ Conidial numbers ( $\log$ transformation) harvested from a 9-cm PDA plate at day 12 after incubation at $28^{\circ} \mathrm{C}$.

y Necrosis area of detached leaves inoculation.

${ }^{\mathrm{z}}$ Percentage of penetration over total number of appressoria at $24 \mathrm{~h}$ postinoculation on onion epidermis. 


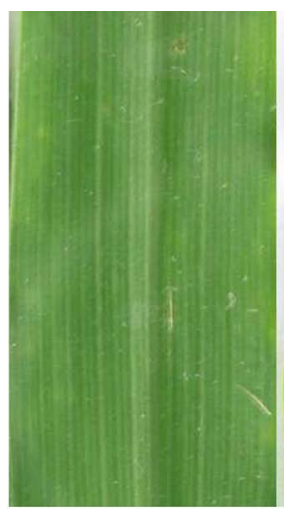

$\mathrm{ddH}_{2} \mathrm{O}$

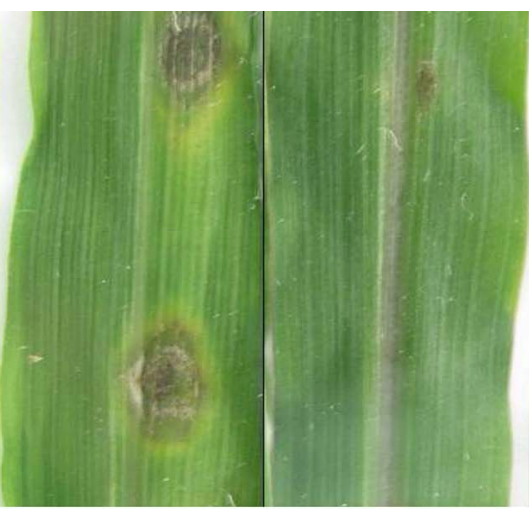

CX-3

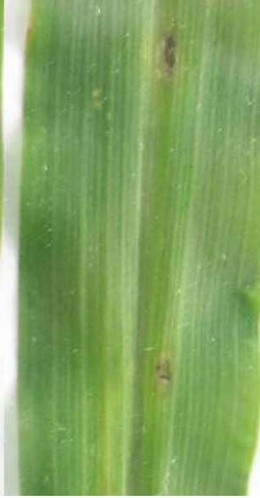

$\Delta \mathrm{Clt}-1$

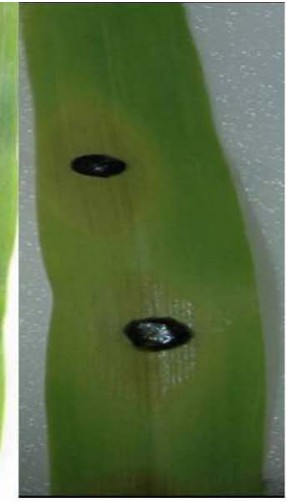

$\Delta$ Clt-1-C

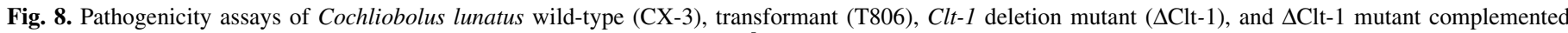
( $\Delta$ Clt-1-C) strains. Lesions on maize leaves in vitro caused by $20 \mu \mathrm{l}$ of $1 \times 10^{5}$ conidia/ml suspension of CX-3, T806, $\Delta \mathrm{Clt}-1$, and $\Delta \mathrm{Clt}-1-\mathrm{C}$.

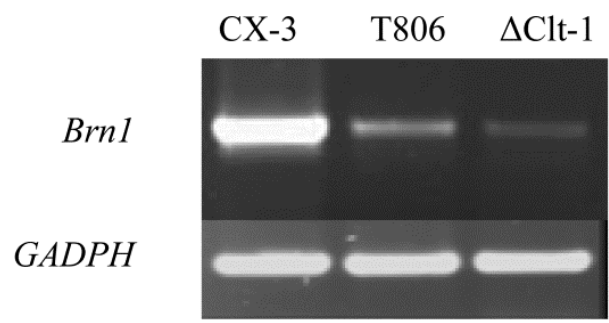

Fig. 9. Reverse-transcription polymerase chain reaction analysis of Brnl (GenBank accession number DQ358052) to be used in melanin production in wild-type (CX-3) and mutant strains. Expression of GADPH (GenBank accession number X58718.1) indicates relative RNA quantity in each sample. Brnl is downregulated in transformant T806, whereas Clt-1 deletion mutant $\Delta$ Clt-1 is downregulated by WT.

associated with toxin and melanin production in a similar regulation pattern.

Clt-1 may be involved in C. lunatus conidiation. T806 and $\Delta$ Clt-1 showed reduced virulence in maize leaves in the present work. Spores from both mutants germinated and produced normal appressoria (data not shown) but the number of conidia was reduced by an order of magnitude compared with the WT. Both were unable to colonize on maize leaves as extensively as the WT. Targeted deletion of $\mathrm{Clt}-\mathrm{I}$ did not affect vegetative growth on PDA medium; therefore, the successful infection of the pathogen was expected to not fully rely on its fast growth. The rate of conidia production is also a determining factor for the virulence of the pathogen (33).

In previous field investigation, we found that $C$. lunatus cannot only infect the maize leaf but also the ear, particularly when the disease occurs seriously in the field. Therefore, some contamination of the ear by toxin poses a potential risk to food safety for humans and livestock. From this point of view, understanding the toxin synthesis-related gene $(\mathrm{Clt}-\mathrm{I})$ would provide a crucial target for breeding varieties resistant to toxin production during pathogen infection. Moreover, we also implied that $\mathrm{Clt}-1$ may be involved in synergistic production of toxin and melanin even though, at present, we don't know how both are connected. As to the finding that deletion of $C l t-1$ reduced spore production, we expected some connection between Clt-1 and other genes directly responsible for spore production. Probably the gene may be one of the node genes responsible for regulating wide expression of multi-pathogenicity genes in the network. These findings have a broad relevance to disease prevention strategies; for instance, against $C l t-1$ gene, we can breed new resistant plants or develop novel chemical fungicides.

\section{ACKNOWLEDGMENTS}

J.-X. Gao and T. Liu contributed equally to this work. This work was supported by grants from China Agriculture Research System (CARS-02), and the National Natural Science Foundation of China (31171798)

\section{LITERATURE CITED}

1. Altschul, S. F., Gish, W., Miller, W., Myers, E. W., and Lipman, D. J. 1990. Basic local alignment search tool. J. Mol. Biol. 215:403-410.

2. Bardwell, V. J., and Treisman, R. 1994. The POZ domain: A conserved protein-protein interaction motif. Genes Dev. 8:1664-1677.

3. Chang, P. K. 2003. The Aspergillus parasiticus protein AFLJ interacts with the aflatoxin pathway-specific regulator AFLR. Mol. Genet. Genomics 268:711-719.

4. Chen, J. S., Zheng, W., Zheng S. Q., Zhang, D. M., Sang, W. J., Chen, X., Li G. P., Lu, G. D., and Wang, Z. H. 2008. Rac1 is required for pathogenicity and Chem1-dependent conidiogenesis in rice fungal pathogen Magnaporthe grisea. PLoS Pathog. 4:e1000202.

5. Chen, X., Stone, M., Schlagnhaufer, C., and Romaine, C. P. 2000. A fruiting body tissue method for efficient Agrobacterium transformation of Agaricus bisporus. Appl. Environ. Microbiol. 66:4510-4513.

6. Dai, F. C., Gao, W. D., Wu, R. J., and Jin, X. H. 1995. A noticeable corn disease: Curvularia leaf spot. Acta Phytopathol. Sin. 25:330.

7. Dai, F. C., Wang, X. M., Zhu, Z. D., Gao, W. D., and Huo, N. X. 1998. Curvularia leaf spot of maize: Pathogens and varietal resistance. Acta Phytopathol. Sin. 2:123-129.

8. de Groot, M. J. A., Bundock, P., Hooykaas, P. J. J., and Beijersbergen, A. G. M. 1998. Agrobacterium tumefaciens-mediated transformation of filamentous fungi. Nat. Biotechnol. 16:839-842.

9. Dong, J. G., Li, Z. P., Xue, F., and Li, G. S. 1997. Structural determination of Ht-toxin component and comparison of the toxicity among ITS analogues. Acta Phytopathol. Sin. 27:257-261.

10. Fu, J., Hettler, E., and Wickes, B. L. 2006. Split marker transformation increases homologous integration frequency in Crytococcus neoformans. Fungal Genet. Biol. 43:200-212.

11. Fu, K. H., Liu, L. X., Fan, L. L., Liu, T., and Chen, J. 2010. Accumulation of copper in Trichoderma reesei transformants, constructed with the modified Agrobacterium tumefaciens-mediated transformation technique. Biotechnol. Lett. 32:1815-1820.

12. Gao, S. G., Zhou, F. H., Liu, T., Li, Y. Y., and Chen, J. 2012. A MAP kinase gene, $C l k 1$, is required for conidiation and pathogenicity in the phytopathogenic fungus Curvularia lunata. J. Basic Microbiol. 52:1-10.

13. Giesbert, S., Schumacher, J., Kupas, V., Espino, J., Segmüller, N., Haeuser-Hahn, I., Schreier, P., and Tudzynski, P. 2012. Identification of pathogenesis-associated genes by T-DNA-mediated insertional mutagenesis in Botrytis cinerea: A type 2A phosphoprotein phosphatase and an SPT3 transcription factor have significant impact on virulence. Mol. Plant-Microbe Interact. 25:481-495.

14. Kawamura, C., Tsujimoto, T., and Tsuge, T. 1999. Targeted distribution of a melanin biosynthesis Gene affects conidial development and UV Tolerance in the Japanese Pear pathotype of Alternaria alternata. Mol. Plant-Microbe Interact. 12:59-63.

15. Koonin, E. V., Senkevich, T. G., and Chemos, V. I. 1992. A family of 
DNA virus genes that consists of fused portions of unrelated cellular genes. Trends Biochem. Sci. 17:213-214.

16. Langfelder, K., Streibel, M., Jahn, B., Haase, G., and Brakhage, A. A. 2003. Biosynthesis of fungal melanins and their importance for human pathogenic fungi. Fungal Genet. Biol. 38:143-158.

17. Lee, Y. H., and Dean, R. A. 1993. cAMP regulates infection structure formation in the plant pathogenic fungus Magnaporthe grisea. Plant Cell 5:693-700.

18. Liu, T., Liu, L. X., Jiang, X., Hou, J. M., Fu, K. H., Zhou, F. H., and Chen, J. 2010. Agrobacterium-mediated transformation as a useful tool for the molecular genetic study of the phytopathogen Curvularia lunata. Eur. J. Plant Pathol. 126:363-371.

19. Liu, T., Liu, L. X., Jiang, X., Huang, X. L., and Chen, J. 2009. A new furanoid toxin produced by Curvularia lunata, the causal agent of maize Curvularia leaf spot. Can. J. Plant Pathol. 31:22-27.

20. Liu, T., Xu, S. F., Liu, L. X., Zhou, F. H., Hou, J. M., and Chen J. 2011. Cloning and characteristics of Brnl gene in Curvularia lunata causing leaf spot in maize. Eur. J. Plant Pathol. 131:211-219.

21. Macri, F., and Lenna, P. 1974. Leaf corn blight incited by Curvularia lunata (Wakk.) Boed. J. Plant Pathol. 10:27-35.

22. Meyer, V., Mueller, D., Strowig, T., and Stahl, U. 2003. Comparison of different transformation methods for Aspergillus giganteus. Curr. Genet. 43:371-377.

23. Michielse, C. B., Hooykaas, P. J. J., van den Hondel, C. A. M. J. J., and Ram, A. F. J. 2005. Agrobacterium-mediated transformation as a tool for functional genomics in fungi. Curr. Genet. 48:1-17.

24. Michielse, C. B., Van Wijk, R., Reijnen, L., Cornelissen, B. J., and Rep, M. 2009. Insight into the molecular requirements for pathogenicity of Fusarium oxysporum f. sp. lycopersici through large-scale insertional mutagenesis. Genome Biol. 10:R4.

25. Numoto, M., Niwa, O., Kaplan, J., Wrong, K. K., Merrell, K., Kamiya,
K., Yanagihara, K., and Calame, K. 1993. Transcriptional repressor ZF5 identifies a new conserved domain in zinc finger proteins. Nucleic Acids Res. 21:3767-3775.

26. Stogios, P. J., Down, G. S., Jauhal, J. J. S., Nandra, S. K., and Prive, G. G. 2005. Sequence and structural analysis of BTB domain proteins. Genome Biol. 6:R82.

27. Tang, J., Liu, L. X., Hu, S. F., Chen, Y. P., and Chen, J. 2009. Improved degradation of organophosphate dichlorvos by restriction enzymemediated integration (REMI). Bioresource Technol. 100:480-483.

28. Torrado, R. P., Yamada, D., and Defossez, P. A. 2006. Born to bind: The BTB protein-protein interaction domain. Bioessays 28:1194-1202.

29. Wang, J. Y., and Chen, J. 2011. Cloning and functional analysis of Clm1 in Curvularia lunata. Acta Phytopathol. Sin. 41:464-472.

30. Xu, J. R., Urban, M., Sweigard, J. A., and Hamer, J. E. 1997. The CPKA gene of Magnaporthe grisea is essential for appressorial penetration. Mol. Plant-Microbe Interact. 10:187-194.

31. Yabe, K., and Nakajima, H. 2004. Enzyme reactions and genes in aflatoxin biosynthesis. Appl. Microbiol. Biot. 64:745-755.

32. Yan, H. H., Chen, J., Xia, S. C., Liu, P., and Gao, Z. G. 2002. Albinism isolates of Curvularia lunata. Mycosystema 21:604-606.

33. Yi, M., Park, J. H., Ahn, J. H., and Lee, Y. H. 2008. MoSNF1 regulates sporulation and pathogenicity in the rice blast fungus Magnaporthe oryzae. Fungal Genet. Biol. 45:1172-1181.

34. You, B. J., Lee, M. H., and Chung, K. K. 2009. Gene-specific disruption in the filamentous fungus Cercospora nicotianae using a split-marker approach. Arch. Microbiol. 191:615-622.

35. Zollman, S., Godt, D., Prive, G. G., Couderc, J. L., and Laski, F. A. 1994 The BTB domain, found primarily in zinc finger proteins, defines an evolutionarily conserved family that includes several developmentally regulated genes in Drosophila. Proc. Natl. Acad. Sci. USA 91:1071710721 